\title{
STUDIES ON MYCOBACTERIUM CHELONEI
}

\author{
J. L. Stanford*, S. R. Pattyn $\dagger$, F. Portaels $\dagger$ and W. J. Gunthorpe* \\ * The School of Pathology, Middlesex Hospital Medical School, London, W.1, \\ and $\dagger$ Prins Leopold Instituut voor Tropische Geneeskunde, Antwerp
}

IT has recently been claimed (Stanford and Beck, 1969) that Mycobacterium abscessus, Myco. borstelense and Myco. runyonii are the same species as the turtle tubercle bacillus of Friedmann (1903) for which the valid name is Myco. chelonei Bergey et al. (1923). Other workers have shown Myco. abscessus and Myco. runyonii to be identical, and have either considered Myco. borstelense to be a separate species (Weiszfeiler, Karasseva and Karczag, 1969; Tsukamura, 1970), or to be a variety of Myco. abscessus (Jenkins, Marks and Schaefer, 1971). In order to determine whether there are one or two species, and whether they have different geographical distributions, we have studied 40 strains from three different continents, including the type strains of each taxon.

\section{MATERIALS AND METHODS}

Before inclusion in this study, all strains were tested to ensure that they possessed the common characteristics of the taxa under review. Thus they were shown to split glucose, mannose and trehalose, but not arabinose, fructose or xylose, and to produce arylsulphatase but not nitrate reductase. They were unable to hydrolyse Tween 80 or to reduce ferric ammonium citrate.

\section{The strains}

1. Twenty-one strains of European origin: the type strains of Mycobacterium chelonei (NCTC no. 946 and strain ART "Bacille de Friedmann" of the Institut Pasteur, Paris), Myco. borstelense (ATCC no. 19235), and Myco. borstelense var. niacinogenes (ATCC no. 19237); seven strains from an outbreak of injection abscesses in Holland, two strains from a similar but smaller outbreak in England, and one strain from an abscess in Belgium; five strains that had been distributed as part of an international co-operative study; two other strains isolated in England, one from the sputum of a man with bacteriologically confirmed tuberculosis of the lung and the other from the sides of a cold-water storage tank.

2. Ten strains of American origin comprised the type strains of Myco. abscessus (ATCC no. 19977), and Myco. runyonii (NCTC no. 10269), seven strains distributed as part of an international co-operative study, and one strain isolated from lung tissue from a man with pulmonary disease.

3. Nine strains of African origin had all been isolated from injection abscesses in the Republic of Zaire.

\section{Methods}

Cultural tests. These were selected for their ability to differentiate between the taxa under examination. (1) Colonial appearance after culture for $8-10$ days at $37^{\circ} \mathrm{C}$ on Dubos oleic acid agar (Kestle, Abbott and Kubica, 1967). This test has the additional advantage of acting as a purity control, since other mycobacteria that might be present as contaminants

Received 3 Mar. 1971; accepted 23 June 1971.

J. MED. MICROBIOL.-VOL. 5 (1972) 
differ from the species under review in their cultural appearance on this medium (Pattyn and Portaels, in preparation). (2) Ability to grow on corn-meal agar. (3) Ability to grow on MacConkey medium after incubation for 15 days at $37^{\circ} \mathrm{C}$ (Desmyter, 1962). (4) Sensitivity to ethambutol (Portaels and Pattyn, 1971). (5) Ability to utilise citrate (Gordon and Mihm, 1959). (6) Growth in the presence of 5 per cent. sodium chloride (Tsukamura). (7) Growth in the presence of $0 \cdot 2$ per cent. picric acid (Tsukamura). (8) Production of nicotinic acid (Bönicke and Ewoldt, 1965).

Serological tests. All strains were examined by immunodiffusion analysis, reactants being prepared by the methods previously described (Stanford and Beck, 1968; Stanford and Gunthorpe, 1971). Antisera were raised in rabbits to the type strains of Myco. abscessus and Myco. runyonii, and to the two strains isolated from injection abscesses in England. Antigens prepared from all 40 strains were tested with each of the antisera and the resulting patterns of immune precipitates were recorded. Antigens of representative strains were then tested with the antiserum to Myco. runyonii after absorption with the antigens of one of the two English abscess strains, and with the antiserum to one of these latter strains after absorption with the antigens of Myco. runyonii.

Agglutination studies were performed by the methods previously described (Schaefer, 1965; Pattyn, 1970). Antisera were raised in rabbits to the type strains of Myco. abscessus and Myco. borstelense, for both direct agglutination and cross-absorption tests. All strains that formed stable, smooth suspensions were examined in the direct tests with both antisera. The antisera were absorbed with each of six European, two African and four American strains by incubation of a mixture of one part of a thick suspension of the absorbing organism and two parts of a one in ten dilution of the antiserum at $37^{\circ} \mathrm{C}$ for 24 or $48 \mathrm{hr}$. These mixtures were shaken frequently during incubation, and then centrifuged. The supernatants were further diluted and tested for their ability to agglutinate each of the suspensions of organisms.

\section{RESULTS}

Approximately three-quarters of the American and European strains produced rough colonies on Dubos agar, and the remaining quarter produced either a predominance of smooth colonies or an equal mixture of rough and smooth colonies. Amongst the African strains, eight produced smooth colonies on Dubos medium, and one produced a mixture of rough and smooth colonies.

Only 11 of the European strains grew on corn-meal agar and in most cases their growth was poor, whereas all the American strains and seven out of nine of the African strains produced good growth on this medium.

The American strains and eight of the nine African strains grew on MacConkey medium, producing grey or faintly pink colonies, whereas none of the European strains grew on this medium.

In agreement with a previous report (Portaels and Pattyn) the majority ( 35 of 40 ) of the strains were highly resistant to ethambutol. However, five strains were sensitive to $5 \mu \mathrm{g}$ per $\mathrm{ml}$ of the drug. Four of these sensitive strains were European in origin and one was American.

One of the European strains, all of the American strains and eight of the nine African strains grew in the presence of 5 per cent. sodium chloride; eight of the ten American strains and six of the nine African strains also grew in the presence of 0.2 per cent. picric acid. All but one of the European strains, none of the American strains and one of the African strains were able to utilise citrate. One of the European strains alone was shown to produce nicotinic acid. These results are shown in the table. 
TABLE

Results of tests enabling differentiation to be made between the varieties of Mycobacterium chelonei

\begin{tabular}{|c|c|c|c|c|c|c|c|c|c|}
\hline \multirow{3}{*}{$\begin{array}{l}\text { Strains classified } \\
\text { according to their } \\
\text { geographical origin }\end{array}$} & \multicolumn{7}{|c|}{ Results of cultural tests* } & \multirow{2}{*}{\multicolumn{2}{|c|}{$\begin{array}{c}\text { Number of } \\
\text { antigens } \\
\text { demonstrated } \dagger \\
\text { with antisera to }\end{array}$}} \\
\hline & \multirow[b]{2}{*}{ 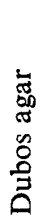 } & \multirow{2}{*}{ 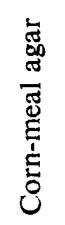 } & \multirow{2}{*}{ 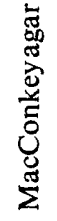 } & \multirow[b]{2}{*}{ 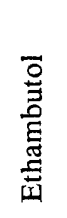 } & \multirow{2}{*}{ 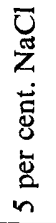 } & \multirow[b]{2}{*}{ 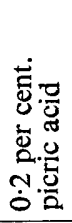 } & \multirow[b]{2}{*}{ 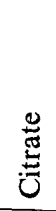 } & & \\
\hline & & & & & & & & 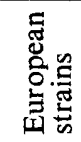 & 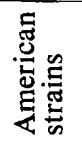 \\
\hline \multicolumn{10}{|l|}{ European } \\
\hline Myco. chelonei NCTC no. 946 & $\mathbf{r}$ & + & - & $\mathbf{S}$ & - & - & + & 11 & 10 \\
\hline Myco. chelonei Inst. Past. & $\mathbf{r}$ & + & - & $\mathbf{S}$ & - & - & + & 11 & 10 \\
\hline Myco. borstelense ATCC no. 19235 & s & + & - & $\mathrm{R}$ & - & - & + & 11 & 10 \\
\hline $\begin{array}{l}\text { Myco. borstelense var. niacinogenes } \\
\text { ATCC no. } 19237\end{array}$ & $r / s$ & + & - & $\mathbf{S}$ & - & - & + & 11 & 10 \\
\hline Dutch strain no. 1 & $\mathrm{r}$ & + & - & $\mathbf{R}$ & - & - & + & 11 & 10 \\
\hline Dutch strain no. 2 & $\mathrm{r}$ & - & - & $\mathbf{R}$ & - & - & + & 11 & 10 \\
\hline Dutch strain no. 3 & $\mathbf{r}$ & - & - & $\mathbf{R}$ & - & - & + & 11 & 10 \\
\hline Dutch strain no. 4 & $\mathrm{r}$ & - & - & $\mathbf{R}$ & - & - & + & 11 & 10 \\
\hline Dutch strain no. 5 & $\mathrm{r}$ & - & - & $\mathrm{R}$ & - & - & + & 11 & 10 \\
\hline Dutch strain no. 6 & $\mathrm{r}$ & - & - & $\mathbf{R}$ & - & - & + & 11 & 10 \\
\hline Dutch strain no. 7 & $\mathrm{r}$ & - & - & $\mathbf{R}$ & - & - & + & 11 & 10 \\
\hline English strain no. 1 & $\mathbf{r}$ & - & - & $\mathbf{R}$ & - & - & + & 11 & 10 \\
\hline English strain no. 2 & s & - & - & $\mathbf{R}$ & - & - & + & 11 & 10 \\
\hline English strain (sputum) no. 3 & s & + & - & $\mathbf{R}$ & - & - & + & 11 & 10 \\
\hline English strain (water tank) no. 4 & $\mathrm{~s}$ & - & - & $\mathbf{R}$ & - & - & + & 11 & 10 \\
\hline Belgian strain & $\mathbf{s}$ & - & - & $\mathbf{S}$ & - & - & + & 11 & 10 \\
\hline International study strain no. 1 & $\mathbf{r}$ & + & - & $\mathbf{R}$ & - & - & + & 11 & 10 \\
\hline International study strain no. 2 & $\mathbf{r}$ & + & - & $\mathbf{R}$ & + & - & - & 10 & 12 \\
\hline International study strain no. 3 & $\mathbf{r} / \mathbf{s}$ & + & - & $\mathbf{R}$ & - & - & + & 11 & 10 \\
\hline International study strain no. 4 & $\mathrm{r}$ & + & - & $\mathbf{R}$ & - & - & + & 11 & 10 \\
\hline International study strain no. 5 & $\mathbf{r}$ & + & - & $\mathbf{R}$ & - & - & + & 11 & 10 \\
\hline \multicolumn{10}{|l|}{ American } \\
\hline Myco. abscessus ATCC 19977 & $\mathrm{~s}$ & + & + & $\mathbf{R}$ & + & + & - & 10 & 12 \\
\hline Myco. runyonii NCTC 10269 & $\mathrm{r}$ & + & + & $\mathbf{R}$ & + & + & - & 10 & 12 \\
\hline Lung resection strain & $\mathrm{r}$ & + & + & $\mathbf{R}$ & + & + & - & 10 & 12 \\
\hline International study strain no. 1 & $\mathrm{r} / \mathrm{s}$ & + & + & $\mathbf{R}$ & + & + & - & 10 & 12 \\
\hline International study strain no. 2 & $\mathrm{r} / \mathrm{s}$ & + & + & $\mathbf{R}$ & + & + & - & 10 & 12 \\
\hline International study strain no. 3 & s & + & + & $\mathbf{R}$ & + & + & - & 10 & 12 \\
\hline International study strain no. 4 & $\mathrm{r}$ & + & + & $\mathbf{S}$ & + & - & - & 10 & 12 \\
\hline International study strain no. 5 & $\mathbf{r}$ & + & + & $\widetilde{R}$ & + & + & - & 10 & 12 \\
\hline International study strain no. 6 & $\mathrm{r}$ & + & + & $\mathbf{R}$ & + & - & - & 10 & 12 \\
\hline International study strain no. 7 & $r / s$ & + & + & $\mathbf{R}$ & + & + & - & 10 & 12 \\
\hline \multicolumn{10}{|l|}{ African } \\
\hline Kinshasa strain no. 1 & $\mathrm{~s}$ & + & + & $\mathbf{R}$ & + & + & - & 10 & 12 \\
\hline Kinshasa strain no. 2 & $\mathrm{~s}$ & + & + & $\mathrm{R}$ & + & - & - & 10 & 12 \\
\hline Kinshasa strain no. 3 & s & + & + & $\mathrm{R}$ & + & - & - & 10 & 12 \\
\hline Kinshasa strain no. 4 & $\mathrm{~s}$ & + & + & $\mathbf{R}$ & + & - & - & 10 & 12 \\
\hline Kinshasa strain no. 5 & $\mathrm{~s}$ & + & + & $\mathbf{R}$ & + & + & - & 10 & 12 \\
\hline Kinshasa strain no. 6 & $\mathrm{r} / \mathrm{s}$ & + & + & $\mathbf{R}$ & + & + & - & 10 & 12 \\
\hline Kinshasa strain no. 7 & $\mathrm{~s}$ & - & - & $\widehat{R}$ & - & + & + & 11 & 10 \\
\hline Kimpese strain no. 1 & $\mathrm{~s}$ & + & + & $\mathbf{R}$ & + & + & - & 10 & 12 \\
\hline Kimpese strain no. 2 & $\mathrm{~s}$ & - & + & $\mathrm{R}$ & + & + & - & 10 & 12 \\
\hline
\end{tabular}

* Dubos agar: colonial appearances; $\mathrm{r}=$ rough, $\mathrm{s}=$ smooth, $\mathrm{r} / \mathrm{s}=$ equal mixture of rough and smooth colonies. Ethambutol: $\mathrm{R}=$ resistant and $\mathrm{S}=$ sensitive to $5 \mu \mathrm{g}$ per ml. Corn-meal agar, MacConkey agar, 5 per cent. $\mathrm{NaCl}$ and $\mathbf{0} \cdot 2$ per cent. picric acid: $+=$ growth, $-=$ no growth.

Citrate: $+=$ utilisation, $-=$ no utilisation. $\dagger$ In immunodiffusion tests. 


\section{Serological results}

In the immunodiffusion tests the antisera to the two European strains produced identical results. With one exception, the European strains could not be distinguished from one another or from one of the African strains with these sera, each strain producing the same complex of 11 immune precipitates. The remaining strains differed in their common lack of one demonstrable antigen (see the figure).

When tested with the antisera raised against either the type strain of Myco. abscessus or that of Myco. runyonii (both strains of American origin) identical results were also obtained. All the American strains, one European strain and

\begin{tabular}{|l}
\hline Strains \\
$\begin{array}{l}\text { All } 10 \text { American strains, } 8 \text { of } 9 \text { African } \\
\text { strains, and } 1 \text { European strain }\end{array}$ \\
$\begin{array}{l}\text { One African strain and } 20 \text { European } \\
\text { strains }\end{array}$ \\
$\begin{array}{l}\text { Other species of fast-growing myco- } \\
\text { bacteria }\end{array}$
\end{tabular}

* Each hatched area represents possession of an individual antigen.

FIGURE.--Antigenic relationships between the two variants of Mycobacterium chelonei and other fast-growing mycobacteria.

eight African strains produced a pattern of 12 immune precipitates, whereas the remaining strains produced a complex of only ten such precipitates. The results of the tests performed with absorbed sera confirmed these findings.

In the agglutination tests, smooth strains were agglutinated by both the Myco. borstelense and the Myco. abscessus antisera alike. In a few cases where titrations were performed there were no significant differences in the titres obtained with either of the antisera. The cross-absorption studies did not allow differentiation between any of the strains tested.

\section{DisCUSSION}

The results of growth in the presence of 5 per cent. sodium chloride, utilisation of citrate and immunodiffusion studies precisely correlate and divide the strains into two groups. A less precise correlation was achieved with the results of tests for growth on MacConkey medium, on corn-meal agar and in the presence of 0.2 per cent. picric acid. Colonial morphology on Dubos oleic acid medium did not assist in the definition of the two groups, although an interesting finding was the high proportion of smooth strains of African origin in comparison with those isolated in Europe or America. 
All the American strains, eight of the nine African strains and a single European strain made up the group characterised by the ability to grow in the presence of 5 per cent. sodium chloride and the inability to utilise citrate. The type strains of Myco. abscessus and Myco. runyonii belonged to this group. A single African strain and 20 of the 21 European strains, including the type strains of Myco. borstelense and Myco. chelonei, constituted the second group.

Agglutination tests could not distinguish between the representatives of the two groups to which they could be applied. Immunodiffusion tests distinguished between the groups, but at a sub-specific level much in the same way that at least four serotypes can be distinguished in Myco. ranae (Stanford and Gunthorpe, 1969). Previous immunodiffusion studies on Myco. chelonei (Stanford and Beck) although failing to distinguish two serotypes, established the serological relationship between this organism and other fast-growing mycobacteria. The organism was then found to possess six species-specific antigens and six antigens that were shared with the other species. The antigenic differences between the two groups described in the present study are entirely amongst the species-specific antigens, seven of which have now been demonstrated as shown in the figure.

Both groups contained strains isolated as pathogens from human lesions, most of which were injection abscesses. The type strain of Myco. chelonei came from a turtle with severe pulmonary disease, and one of the American strains was isolated from diseased human lung.

When it is taken into account that tests such as utilisation of sugars, arylsulphatase and nitrate reductase activity, ability to hydrolyse Tween 80 , sensitivity to antituberculous drugs and serological agglutination produce identical results in the two groups, the ability to distinguish between them by means of a few specially selected tests can be seen in its true perspective. The evidence of the immunodiffusion tests that the two groups can be differentiated only at a sub-specific level, the different geographic origins of strains of the two groups, and their similar pathogenic significance also suggests that the two groups are geographical variants of a single species.

We conclude, therefore, that strains identified as Myco. abscessus or Myco. runyonii on the one hand, and those identified as Myco. borstelense or Myco. chelonei on the other, are two geographical variants of a single species for which the correct name, on the basis of chronological priority, is Myco. chelonei Bergey et al.

\section{SUMMARY}

Forty strains described as Mycobacterium abscessus, Myco. borstelense, Myco. chelonei or Myco. runyonii, and isolated in three different continents, have been examined culturally, biochemically and serologically. In common with others we were able to divide the strains into two groups, but these were too similar to one another to merit separate specific status. All the American strains, most of the African strains and only one European strain belonged to one group. Twenty out of 21 European strains and a single African strain

J. MED. MICROBIOL.-VOL. 5 (1972) 
constituted the second group. It was concluded that these were two geographical variants of a single species for which the oldest valid name is Mycobacterium chelonei Bergey et al., and it is recommended that this name be adopted.

We wish to thank Dr H. Boisvert of the Institut Pasteur, Paris, Dr J. G. A. Borghans of the Streeklaboratorium voor de Volksgezondheid, Nijmegen, Holland, Dr R. T. Cooke of the General Hospital, West Hartlepool, England, Professor F. Gatti of the Université Lovanium, Kinshasa, Republic of Zaire, Dr T. S. Hosty of the Department of Public Health, Montgomery, Alabama, USA, and Dr W. M. Meyers, of the Institut Médical Evangelique, Kimpese, Republic of Zaire, for the provision of many of the strains.

\section{REFERENCES}

BÖNICKE, R., AND EwOLDT, A. 1965. Quantitative Untersuchungen über das Niacinbildungsvermogen von Mycobacterium borstelense var. niacinogenes. Beitr. Klin. Tuberk., 130, 149.

Desmyter, J. 1962. Deux nouveaux tests de differentiation de mycobactéries à croissance rapide. Annls Soc. belg. Méd. trop., 42, 455.

FrIEDMANN, F. F. 1903. Der Schildkrötentuberkelbacillus, seine Züchtung, Biologie und Pathogenität. Zentbl. Bakt. ParasitKde, I Abt. Orig., 34, 647 and 793.

Gordon, Ruth E., AND MiHM, JoAN M. 1959. A comparison of four species of mycobacteria. J. Gen. Microbiol., 21, 736.

Jenkins, P. A., Marks, J., ANd Schaefer, W. B. 1971. Lipid chromatography and seroagglutination in the classification of rapidly growing mycobacteria. Amer. Rev. Resp. Dis., 103, 179.

Kestle, D. G., Аввотt, Vella D., ANd Kubica, G. P. 1967. Differential identification of mycobacteria II. Subgroups of groups II and III (Runyon) with different clinical significance. Amer. Rev. Resp. Dis., 95, 1041.

PatTyn, S. R. 1970. Agglutination with rapidly growing (Runyon's group IV) mycobacteria. Zentbl. Bakt. ParasitKde, I Abt. Orig., 215, 99.

Pattyn, S. R., AND Portaels, F. In preparation. Identification and clinical significance of mycobacteria.

Portaels, F., and Pattyn, S. R. 1970. Resistance to ethambutol as an aid to the identification of Mycobacterium friedmannii (abscessus) and M. borstelense. J. Med. Microbiol., 3,674 .

SCHAEFER, W. B. 1965. Serologic identification and classification of the atypical mycobacteria by their agglutination. Amer. Rev. Resp. Dis., 92, 85.

StANFord, J. L., AND BECK, A. 1968. An antigenic analysis of the mycobacteria, Mycobacterium fortuitum, Myco. kansasii, Myco. phlei, Myco. smegmatis and Myco. tuberculosis. J. Path. Bact., 95, 131.

StANFORD, J. L., AND BeCK, A. 1969. Bacteriological and serological studies of fast growing mycobacteria identified as Mycobacterium friedmannii. J. Gen. Microbiol., 58, 99.

STANFORD, J. L., AND GUNTHORPE, W. J. 1969. Serological and bacteriological investigation of Mycobacterium ranae (fortuitum). J. Bact., 98, 375.

STANFORD, J. L., AND GUNTHORPE, W. J. 1971. A study of some fast-growing scotochromogenic mycobacteria including species descriptions of Mycobacterium gilvum (new species) and Mycobacterium duvalii (new species). Br. J. Exp. Path., 52, 627.

TsukamURA, M. 1970. Differentiation between Mycobacterium abscessus and Mycobacterium borstelense. Amer. Rev. Resp. Dis., 101, 426.

Weiszfeiler, J. G., Karasseva, Valentina, and Karczag, Erika 1969. Comparative studies on the taxonomic relationship between Mycobacterium abscessus and Mycobacterium borstelense. Acta microbiol. hung., 16, 371. 